\section{A NOTE ON \\ THE BENEFICIAL EFFECT OF THE INGHSTION OF CANE SUGAR IN CERTAIN FORMS OF HEART DISEASE.}

By A. Goulston, M.A., M.B.Cantab., HEAVITREE, EXETER.

THE idea of using sugar for this parpose is somewhat startling, until one has thought over the physiology of sugar for a moment; I shall therefore briefly run through the changes undergone by cane sugar from its ingestion to its storage and use in heart muscle.

That glycogen is essential to healthy, well-nourished muscle is shown by the fact that it furnishes a source of energy for the needs of the tissue cells, and particularly for muscular work. The glycogen of a muscle disappears in proportion to the work done by the muscle, and, indeed, prolonged muscular work, especially in starvation, may wipe out quickly the entire store of glycogen in the body -in the liver as well as in the muscles.

All modern physiologists agree that the glycogen stored up in a muscle is converted into dextrose by an amylolytic ferment before being actually used for producing muscular energy. Such a ferment has been discovered by Nasse. In cane sugar, therefore, we have a simple means for supplying the muscles with dextrose for the purposes of their activity.

All the foregoing is, of course, well-known straightforward physiology, but what is not so generally known, apparently, is that dextrose is capable of nourishing the heart muscle in a most wonderful and peculiar manner. F. S. Locke (King's College, London) has kept the excised mammalian heart beating for ninety-one hours after the death of the animal from which the heart was taken. Perfusion with solution of dextrose was carried out daily for five days, and at the end of that time the heart was beating so regularly that it was used by Professor Halliburton to demonstrate to a class of students. Again F. S. Locke says: "Experiments have been made with galactose, rhamnose, 1-arabinose, and glucoheptose. No action at all comparable to that of dextrose could be found."

I have said enough to show the beneficial effect of dextrose on mammalian heart muscle, and in my hands the good effect of taking cane sugar to improve the nutrition of the musculature of the heart has been quite in accordance with what was to be expected from what is known of the physiology of the subject.

I will now very brielly give a few cases illustrating the clinical value of this mode of treatment of certain forms of heart trouble. I should mention that I have always used Glebe granulated cane sugar, which is, I am told, one of the purest cane sugars on the market.

Definition.-I take the physical signs of dilatation given by Broadbent in his work on the heart. The pulse is irregular in rhythm and unequal in force of beat; usually easily compressed. On deep percussion the heart is more rounded in the apex region than normal, and the area of dullness is greatly extended to the left. The first sound is short and sharp, and it is almost always audible in the aortic area.

Dilated Heart of Advanced Age.

Lady, 74 years of age. Dilated heart, with systolic murmur. Treated with drugs with little benefit. She was so ill that she had to be kept in bed in the recumbent position. She was put on cane sugar, and in the course of three months was able to go ont walking. She has been quite well ever since, but she takes the sugar from time to time when she feels she require it. This lady conld not stand without feeling faint, but for the last four or five years she has been able to travel alone visiting her friends. She is now in her 8lst year, and is quite well and walks out alone daily.

Gentleman, 77 years of age. In the habit of taking alcohol freely. His heart dilated and he was losing flesh. All alcohol was stopped and he was put on the sugar. In three months he was much improved. For the last two years he has enjoyed wonderfully good health. He is rather proud of his achievements in the walking way. Since beginning the sugar treatment he has had an attack of acute bronchitis and one of severe diarrhoea, but he got over both attacks in a wonderful way, and he is now at 80 years of age in excellent health, both mentally and physically.
Valvular Heart Disease.

Woman, 34 years of age. Admitted to hospital August 18th, 1910. August 27th, 1910, the note is: "There are very audible systolic and diastolic murmurs at the aortic base." She was treated for three months without beneftit, and on December lst, 1910, she was put on the sugar. She has now (January 20th 1911) complete compensation, and her pulse is quite regular and of good tension, and she is assisting in the ward work.

Woman, 27 years of age. Admitted to hospital October 27th, 1910. On November 4th, 1910, "the apex beat is 1 inch outside the nipple line. Systolic murmur heard all over the chest, and a pre-systolic murmur at apex." The pulse is hardly perceptible, and her feet, legs, arms, and cheeks are blue (livid). Heert acting extremely feebly. On December lst she was pnt on the ward work. She left the hospital January 20th, 1911.

For the two previous hospital cases I am indebted to the kindness of Dr. H. Davy, who, on December lst, 1910, allowed me to select these cases as suitable for the treatment.

Post-influenzal Dilatation of Heart.

Gentleman, 60 years of age. In September, 1913, he had a sharp attack of influenza, after which his heart dilated with the usual symptoms. He was put on the sugar and improved rapidly, and has been well ever since.

\section{Heart Strain.}

Young man, 21 years of age. For some months has been riding all over Devonshire and Cornwall on a bicycle, carryin a heavy load of books on his back. He now complained of feeling weak, and unable to do his work. His heart was dilated. I ordered rest, and put him on the sugar. This was two years ago. He is now quite well, and there are no signs of his former trouble. I should mention that he suffered from pyorrhuea alveolaris, and it is possible this had something to do with the dilatation as a contributory cause.

Heart Failure in Tuberculous Phthisis.

Woman, 35 years of age. Strong family history of tubercle, from which her father, mother, and brother had died. Eighteen months ago she was extremely thin, and had decided symptoms months ago she was extremely thin, and had decided symptoms
of tuberculous phthisis. The right apex was consolidated, and there was slight expectoration, and she was losing flesh rapidly, and was confined to her bed. I put her on the sugar and Easton's syrup. In the course of six months she improved sufficiently for her to go out of doors for a short walk. Now (January 25th, 1911), she can run and do anything in the way of exercise as other people, and she is getting rid of the slatey appearance of her skin, and has a healthy colour. She has put on flesh and retains it. She still takes the sugar, but not in so large quantities. Her heart symptoms have almost disappeared-that is to say, the dull area is only slightly increased to the left, and the apex beat is nearly in the normal position.

I have had good results also in anaemic cases with dilated hearts and also in a case of chloroform beart.

In all these cases I have rarely found any sugar in the urine although so much sugar was taken; but occasionally there was a trace.

BIBLIOGRAPHY.

Textbook of Physiology, vol. i, edited by E. A. Schäfer. Textbook of Physiology for Medical students and Physicians, by W. H. Howell. F. 8. Locke and O. Rosenheim, Centralblatt fiur Physiologie, Decem ber 30th, 1905, Bd. xix, Nr. 20. F. B. Locke, Journal of Physiology vol. $x \times x i$.

\section{MECHANO-THERAPEUTICS IN THE TREAT- MENT OF CHRONIC CONSTIPATION.}$$
\text { BY }
$$

EDGAR F. CYRIAX, M.D.EdIN. LONDON.

I HAVE followed with great interest the recent discussion on chronic constipation and its treatment, opened by Dr. J. F. Goodhart at the last meeting of the British Medical Association, which was reported in the BRITISH MedICAL JodRNAL for October 8th, 1910. I could not but be struck by the scanty references which the various speakers at the meeting made to the value of mechano.therapy in alleviating the condition referred to.

The movement cure in its modern phase dates back to the commencement of the last century, when it was in. vented by the Swede, P. H. Ling (1776-1839.) After his death his pupils developed the work which he had begun, the chief ones being $L$. G. Branting, Hj. Ling, and $H$. Kellgren. Ling's Swedish treatment, at first entirely empirical, has in the course of a century undergone a development which grounds it firmly on a rational basis of physiology, anatomy, and pathology. 